\title{
Transtorno do Espectro Autista e Práticas Educativas na Educação Profissional ${ }^{1}$ \\ Autism Spectrum Disorder and Educational Practices in Professional EDUCATION
}

\author{
Simone Pinto VASCONCELLOS² \\ Mônica Maria Farid RAHME ${ }^{3}$ \\ Taísa Grasiela Gomes Liduenha GONÇALVES ${ }^{4}$
}

\begin{abstract}
RESUMO: No contexto da educação inclusiva, esta pesquisa teve como objetivo analisar as práticas educativas adotadas na escolarização de um estudante com Transtorno do Espectro Autista (TEA) no Ensino Técnico Integrado (ETI). O estudo foi orientado por uma abordagem qualitativa, na modalidade estudo de caso. Para coleta de dados, realizaram-se uma pesquisa documental e entrevistas semiestruturadas com o estudante com TEA, seus pais e seus professores de uma instituiçáo da Rede Federal de Educação Profissional, Científica e Tecnológica (RFEPCT), em Belo Horizonte, estado de Minas Gerais. Na interpretação dos dados, utilizou-se a análise de conteúdo, com o aporte teórico da educação inclusiva e da literatura sobre o TEA. Os resultados desta investigação apontam para o reduzido número de matrículas de pessoas com autismo no ETI e para a efetividade do trabalho colaborativo, em interlocução com a família, açóes de apoio ao estudante, flexibilização curricular, adequaçóes das avaliaçóes, procedimentos didáticos e propostas de ensino específicas. Essas açóes resultaram em condiçốes mais adequadas de escolarizaçáo para o estudante com autismo, mas com desafios a serem superados, relativos às fragilidades na formação dos educadores e à necessidade de institucionalização de diretrizes e práticas educativas pautadas na diversidade humana, que ampliem as oportunidades educacionais.
\end{abstract}

PALAVRAS-CHAVE: Autismo. Educação profissional. Práticas educativas.

ABSTRACT: In the context of inclusive education, this research had as the objective to analyze the educational practices adopted in the schooling of a student with Autism Spectrum Disorder (ASD) in the Integrated Technical Education. The study was guided by a qualitative approach, as a case study. To collect the data, a documentary research and semi-structured interviews with the student with ASD, his parents and the teachers from the institution of the Federal Network of Professional, Scientific and Technological Education, in Belo Horizonte, State of Minas Gerais, Brazil, were carried out. To interpret the data, the Content Analysis was used, with the theoretical contribution of inclusive education and the literature on ASD. The results of this research point to the low enrollment numbers of people with autism in the Integrated Technical Education and to the effectiveness of the collaborative work, in interaction with the family, support actions for the student, curricular flexibilization, adjustments to assessments, didactic procedures and specific teaching proposals. These practices have resulted in more adequate conditions of schooling for the student with autism, but also with challenges to be overcome, concerning weaknesses in the training of educators and the need for institutionalization of guidelines and educational practices based on human diversity that expand the educational opportunities.

KEYWORDS: Autism. Professional education. Educational practices.

\footnotetext{
${ }^{1}$ https://doi.org/10.1590/1980-54702020v26e0060

${ }^{2}$ Mestra em Educação. Faculdade de Educação (FaE). Universidade Federal de Minas Gerais (UFMG). Belo Horizonte/MG/ Brasil. E-mail: simone.spv@gmail.com. ORCID: https://orcid.org/0000-0001-9190-4125.

${ }^{3}$ Doutora em Educação. Departamento de Ciências Aplicadas à Educação (DECAE). Faculdade de Educação (FaE). Universidade Federal de Minas Gerais (UFMG). Belo Horizonte/MG/Brasil. E-mail: monicarahme@ufmg.br. ORCID: http://orcid.org/00000003-2123-2989.

${ }^{4}$ Doutora em Educação Especial pela Universidade Federal de São Carlos (UFSCar). Departamento de Ciências Aplicadas à Educação (DECAE). Faculdade de Educação (FaE). Universidade Federal de Minas Gerais (UFMG). Belo Horizonte/MG/Brasil. E-mail: taisaliduenha@icloud.com. ORCID: https://orcid.org/0000-0001-5589-584X.
} 


\section{INTRODUÇÁo}

A ampliação do acesso das pessoas com Transtorno do Espectro Autista (TEA) às instituiçóes regulares de educação profissional foi propiciada pela mudança de concepção educacional para o paradigma da educação inclusiva, a partir da segunda metade do século XX, fundamentado na defesa da igualdade de direitos e oportunidades.

Ao longo da história, a educação profissional das pessoas com deficiência ${ }^{5}$ ocorreu de forma paralela ao sistema regular de ensino, em instituiçóes especializadas ou oficinas (Silva $\&$ Dore, 2016), com caráter assistencialista e normalizador (Silva, 2011). A partir da década de 1990, a legislação brasileira e as políticas públicas nacionais, ratificando as diretrizes de documentos internacionais em prol dos direitos humanos, preconizaram a universalização da educação e a igualdade de oportunidades de aprendizagem a todas as pessoas. No Brasil, a ampliação do acesso das pessoas com deficiência à Educação Básica foi marcada inicialmente pela Constituição Federal (1988), que instituiu o dever do Estado de ofertar o Atendimento Educacional Especializado $(\mathrm{AEE})^{6}$ para as pessoas com deficiência, e a Lei de Diretrizes e Bases da Educação Nacional (LDBEN - Lei no 9.394, de 20 de dezembro de 1996), que definiu a Educação Especial ${ }^{7}$ como uma modalidade de ensino oferecida preferencialmente na escola regular.

A partir de 2008, com a formulação da Política Nacional de Educação Especial na Perspectiva da Educaçáo Inclusiva (PNEEPEI), houve uma maior consolidação do acesso desse público ao ensino regular, bem como a definiçáo de que os serviços de apoio especializados deixariam de substituir essa escolarização, tornando-se complementares, no caso das pessoas com deficiência, ou suplementares, para os sujeitos com altas habilidades ou superdotação. Mais recentemente, a Lei Brasileira de Inclusão da Pessoa com Deficiência, Lei no 13.146, de 6 de julho de 2015, assegurou o direito desses sujeitos ao acesso, à permanência, à participação e à aprendizagem em todos os níveis e modalidades de ensino, com a disponibilização de estratégias de acessibilidade em suas diversas dimensóes.

Nesse contexto de mudança da política educacional, buscou-se compreender, na pesquisa desenvolvida, como tem ocorrido a escolarização de jovens com TEA no ensino técnico integrado (ETI), uma modalidade de formação profissional que abrange o Ensino Médio e o Ensino Técnico ministrados na mesma instituição educacional ${ }^{8}$. Por meio de um currículo

\footnotetext{
${ }^{5}$ Neste artigo, será utilizada, preferencialmente, a terminologia "pessoas com deficiência” para reportar aos estudantes da Educaçâo Especial. Ressalta-se que os sujeitos com autismo foram considerados como pessoas com deficiência para todos os efeitos legais pela Lei no 12.764, de 27 de dezembro de 2012, que instituiu a Política Nacional de Proteçáo dos Direitos da Pessoa com Transtorno do Espectro Autista.

${ }^{6}$ O Decreto $n^{\circ} 7.611$, de 17 de novembro de 2011, define o Atendimento Educacional Especializado como o conjunto de atividades, recursos pedagógicos e de acessibilidade, organizados pela instituição educacional de forma contínua, com o objetivo de complementar ou suplementar a formação dos estudantes da Educação Especial no ensino regular. Kassar e Rebelo (2011) explicam que, no período da promulgação da Constituição de 1988, esse atendimento especializado poderia ser oferecido por meio de diferentes modalidades de ensino, de preferência na rede regular de educação.

${ }^{7}$ De acordo com a Lei no 9.394/1996, os estudantes da Educação Especial constituem as pessoas com deficiência, transtornos globais do desenvolvimento, altas habilidades ou superdotação.

${ }^{8}$ Conforme descrito na LDBEN (Lei no 9.394, 1996), a educação profissional engloba cursos de qualificação, de ensino técnico de nível médio, de graduação e pós-graduação. O ensino técnico de nível médio pode ser desenvolvido de forma articulada ao Ensino Médio, para os alunos que concluíram o Ensino Fundamental, e, de forma subsequente, no caso dos que já concluíram a Educação Básica. A educação profissional técnica articulada ao nível médio pode ser realizada de forma integrada na mesma instituição, e de forma concomitante, quando o curso médio e o técnico ocorrem em diferentes estabelecimentos de ensino, com matrículas distintas.
} 
integrado, o ETI apresenta particularidades como a carga horária extensa, rotinas escolares específicas, além de objetivos, conteúdos e metodologia diferenciados do Ensino Médio regular. Tendo em vista essas especificidades, indagou-se sobre quais práticas educativas têm sido adotadas na escolarização dos estudantes com autismo no ETI. Neste estudo, as práticas educativas são compreendidas como o trabalho educativo desenvolvido no âmbito da instituição técnica, o que abrange não somente a prática docente como também as ações educacionais promovidas pelos setores de suporte ao ensino.

Apesar das garantias legais e das diretrizes das políticas educacionais, o ingresso de pessoas com deficiência nos cursos técnicos integrados é bastante reduzido, como indicam os dados das Sinopses Estatísticas da Educação Básica no período de 2014 a 2018 (Instituto Nacional de Estudos e Pesquisas Educacionais Anísio Teixeira [INEP], 2015, 2016, 2017, 2018, 2019), descritos na Tabela 1. Nesse levantamento, não são discriminadas as matrículas dos jovens com TEA, os quais estão contemplados no grupo de estudantes da Educação Especial. O baixo percentual de matrículas, ao longo do período analisado, explicita a dificuldade de acesso ao ETI por parte das pessoas com autismo e dos demais estudantes com deficiência. No ano de 2018, apesar do aumento do acesso desses alunos ao ETI, as matrículas da Educação Especial corresponderam a apenas $0,5 \%$ do total nos cursos técnicos integrados em Belo Horizonte $(\mathrm{BH})$, Minas Gerais, como apresenta a Tabela 1.

\begin{tabular}{|c|c|c|c|c|c|}
\hline Matrículas no ETI/ Período & 2014 & 2015 & 2016 & 2017 & 2018 \\
\hline Gerala $^{a}$ & 3.019 & 2.539 & 2.520 & 2.424 & 3.195 \\
\hline Educação Especial ${ }^{b}$ & 4 & 7 & 4 & 5 & 16 \\
\hline
\end{tabular}

Tabela I. Matrículas da Educação Especial em classes comuns no Ensino Médio Integrado em Belo Horizonte.

Fonte: As autoras com base nas Sinopses Estatísticas da Educação Básica (INEP, 2015, 2016, 2017, 2018, 2019). Notas: (a) inclui as matrículas das instituiçōes de ensino federais, estaduais, municipais e privadas; (b) inclui as matrículas de estudantes com deficiência, transtorno global do desenvolvimento9 ou altas habilidades/superdotação.

A respeito dessa limitação no acesso à educação profissional, Cordeiro (2013) observou que as pessoas com deficiência apresentavam trajetórias predominantemente não lineares, em escolas públicas. De acordo com a análise da autora, a precariedade do percurso escolar desses estudantes provocaria um afunilamento na passagem para o Ensino Médio pela não conclusão do Ensino Fundamental, assim como por dificuldades na realização das provas de conhecimento que compóem os processos seletivos das escolas técnicas. Quanto ao processo educativo dos estudantes com TEA, o estudo de Lima e Laplane (2016) reforça os achados de Goessler (2016) ao identificar que a maioria deles, cerca de 92\%, apresentou uma trajetória escolar parcial ou incompleta, o que indicaria a existência de obstáculos à permanência na escola, principalmente nas séries finais do Ensino Fundamental na Rede Municipal. Dessa forma, as

\footnotetext{
${ }^{9}$ Antes da adoção da terminologia Transtorno do Espectro Autista, a 4a edição do Manual Diagnóstico e Estatístico de Transtornos Mentais (DSM IV) utilizava a categoria diagnóstica Transtornos Globais do Desenvolvimento (TGD), que incluía o Autismo, a Síndrome de Asperger, a Síndrome de Rett, o Transtorno Desintegrativo da Infância e o Transtorno Global do Desenvolvimento, sem outras especificaçōes (Schmidt, 2017).
} 
autoras constataram o alto índice de evasão escolar desses estudantes, visto que poucos chegavam ao Ensino Médio (Lima \& Laplane, 2016).

Para o restrito número de jovens com TEA que conseguiram superar os obstáculos presentes na escolarização, no Ensino Fundamental e no processo de ingresso aos cursos técnicos, ainda podem se impor desafios ao longo do percurso do ensino técnico. Nesse sentido, estudos demonstram a falta de políticas e de açóes institucionalizadas na perspectiva de uma educação inclusiva, a ausência de adequaçóes que tornem as práticas educativas acessíveis a esses jovens, além de fragilidades na formação dos educadores (Oliveira, 2014; Rodrigues, 2014). Nesse tocante, Goessler (2016) observou que o percurso de interrupçóes na escolarização das pessoas com deficiência se repetia na educação profissional, de forma que a maioria não finalizou o curso técnico. A autora ressaltou, entretanto, que essa questão não se restringia aos estudantes com deficiência.

Os resultados desses estudos indicam a necessidade de reflexão sobre como as práticas educativas escolares podem ser mais acessíveis aos estudantes com autismo, tendo em vista as especificidades que esses jovens apresentam. Para tanto, é importante compreender que o TEA se refere a um continuum de transtornos do neurodesenvolvimento cujos critérios diagnósticos compreendem dois âmbitos: dificuldades na comunicação social e na interação social; e padróes restritos e repetitivos de comportamentos, interesses ou atividades (American Psychological Association [APA], 2014). As dificuldades nesses dois domínios estão presentes desde a infância e podem se manifestar de diversas formas, com intensidades que transitam de leve a grave, $o$ que repercute no tipo de apoio que o sujeito requer (APA, 2014). Contudo, deve-se considerar que a gravidade das manifestaçóes do autismo pode variar de acordo com o contexto e o momento da vida (APA, 2014).

O autismo foi descrito como uma categoria nosográfica específica, na década de 1940, pelos psiquiatras Leo Kanner (Kanner, 2012) e Hans Asperger (Asperger, 2015), mas apenas em 1980 foi inserido como uma nova classe de transtornos no Manual Diagnóstico e Estatístico de Transtornos Mentais. A partir da $5^{a}$ edição desse manual, passou-se a adotar a terminologia Transtorno do Espectro Autista (TEA) com o objetivo de expressar a variedade de manifestaçóes relativas às dificuldades sociocomunicacionais e comportamentais vivenciadas pelas pessoas com TEA. Segundo dados disponibilizados pelo Centro de Controle e Prevenção de Doenças (Centers for Disease Control and Prevention - CDC) dos EUA ${ }^{10}$, o autismo é encontrado em todos os grupos étnico-raciais e socioeconômicos, e ocorre quatro vezes mais em meninos do que em meninas. O CDC estima que uma em cada 54 crianças apresenta o autismo nesse país. No Brasil, não há dados oficiais sobre a prevalência do TEA, mas estima-se que aproximadamente dois milhóes de pessoas apresentem essa condição, de acordo com os critérios diagnósticos (Fadda \& Cury, 2016). A causalidade do autismo ainda não foi totalmente definida, mas, segundo Fadda e Cury (2016), a tese mais aceita atualmente refere-se à visão de que uma combinação de fatores genéticos e ambientais altera o funcionamento cerebral das pessoas com autismo.

\footnotetext{
${ }^{10}$ Informaçōes disponíveis no endereço eletrônico do CDC. Recuperado em 27 mar. 2020 de https://www.cdc.gov/ncbddd/ autism/data.html.
} 
Tendo em vista as particularidades apresentadas pelas pessoas com TEA, este trabalho teve com objetivo geral analisar as práticas educativas adotadas no processo de escolarização de um estudante com TEA no Ensino Técnico Integrado, a partir das percepçóes desse jovem, de seus pais e dos seus professores. Os objetivos específicos desta pesquisa consistiram em identificar as percepçóes do aluno com autismo, de seus pais e seus docentes a respeito das práticas educativas adotadas no ETI e analisar a contribuição dessas açóes para a escolarização do estudante na Educação Profissional Técnica Integrada.

\section{Metodologia}

Para alcance dos objetivos apresentados, foi realizada uma pesquisa qualitativa, na modalidade estudo de caso, a partir da experiência de um jovem com TEA, matriculado no curso técnico da área de informática de uma instituição técnica da Rede Federal de Educação Profissional, Científica e Tecnológica, localizada no município de Belo Horizonte, Minas Gerais. Os dados foram coletados por meio de pesquisa documental e de entrevistas semiestruturadas, realizadas com o estudante com autismo, seus pais e com os professores que lecionaram para esse jovem, ao longo de sua trajetória no curso técnico integrado da referida escola. A proposta de pesquisa foi avaliada pelo Comitê de Ética da instituição investigada que aprovou a sua realização, com o Certificado de Apresentação para Apreciação Ética (CAAE). O estudo contou com dez participantes voluntários, que não receberam remuneração por essa participação: um estudante com o diagnóstico de TEA, o pai e a mãe desse jovem e sete docentes do ETI. A seleção dos participantes ocorreu a partir da identificação do único discente que declarou apresentar autismo na instituição investigada, no período de desenvolvimento desta pesquisa. Por conseguinte, foram identificados os pais desse estudante e os professores que ministraram aulas para o jovem com TEA no ensino técnico integrado. Dentre esses docentes, foram selecionados aqueles que concordaram em participar desta pesquisa, o que representou aproximadamente $36 \%$ do total de professores vinculados ao curso técnico da área de informática, entre os anos de 2016 e 2018 (período entre o ingresso do estudante na escola e a realização da pesquisa).

As entrevistas foram realizadas em uma sala de aula da instituição técnica, em cinco momentos distintos: com o estudante com TEA, de forma individual; com os pais, em dupla; e com os professores ocorreu em três formatos: em grupo (com quatro docentes), em dupla e individualmente. Na condução, foi utilizado um roteiro de forma flexível, com perguntas abertas sobre a escolarização do jovem com autismo no curso técnico integrado, em termos dos aspectos facilitadores e dificultadores dessa experiência, das interaçóes sociais no ambiente escolar e das práticas educativas adotadas pela instituição técnica federal, inclusive sobre as dificuldades de implementação e contribuições dessas ações ao processo educativo do estudante. Essas questóes foram apresentadas a todos os participantes e outros tópicos foram abordados em grupos específicos de entrevistados. Aos docentes, também foram propostas perguntas referentes aos conhecimentos sobre o TEA, à experiência anterior com estudantes com essa condição e à participação da família na vida escolar do jovem com autismo. Aos pais e ao estudante, foram apresentadas questóes sobre a trajetória escolar anterior ao ETI, a escolha pelo curso técnico, a preparação para o processo seletivo da instituição técnica federal e a implementação de adaptaçóes nas provas de seleção para o curso técnico integrado. Todas as entrevistas foram gravadas em áudio, com a concordância dos participantes, e transcritas integralmente. 
O material das entrevistas foi contextualizado e complementado pelos dados levantados na pesquisa documental que consistiu na análise dos seguintes documentos institucionais: projeto político pedagógico, proposta de organograma administrativo, resolução sobre os conselhos de classe, editais dos processos seletivos para os cursos técnicos integrados, nota explicativa sobre a elegibilidade para as vagas reservadas às pessoas com deficiência no processo seletivo, dados da Comissão Permanente de Vestibular sobre o número de candidatos com deficiência e necessidades de adaptação no processo seletivo, boletim escolar do estudante com TEA de 2016, 2017 e 2018, plano de ensino de uma disciplina de ciências exatas e relatório do setor de acompanhamento psicossocial dos discentes.

Os conteúdos obtidos pela coleta de dados foram analisados pelo método de análise de conteúdo, buscando-se significados a partir da correspondência entre as "estruturas semânticas ou linguísticas e as estruturas psicológicas ou sociológicas (por exemplo, condutas, ideologias ou atitudes) dos enunciados" (Bardin, 2011, p. 43). O processo de análise dos dados consistiu em três fases: (1) pré-análise, na qual foram selecionados os documentos institucionais, transcritas as entrevistas e realizada a leitura do material coletado; (2) exploração do material e tratamento dos dados, que envolveu a codificação dos textos obtidos com as transcriçóes das entrevistas e dos documentos institucionais, cujos conteúdos foram organizados em categorias temáticas; (3) inferência e interpretação dos conteúdos, com a identificação dos significados associados aos temas, a partir do aporte teórico referente à educação inclusiva e ao TEA.

\section{Resultados}

Os dados sobre a escolarização do estudante com autismo no ETI foram organizados em três categorias principais relacionadas ao objetivo deste estudo, conforme descrito neste tópico: fatores facilitadores, fatores dificultadores e práticas educativas adotadas com o estudante com TEA, que abrange as subcategorias: açóes de apoio aos estudantes, trabalho colaborativo, flexibilização curricular, monitoria individualizada, proposta de ensino e procedimentos didáticos.

\subsection{Fatores facilitadores e dificultadores no Ensino Técnico InTEgrado}

Ao longo do ensino técnico integrado, alguns fatores favoreceram a permanência e os avanços na escolarização do estudante com TEA, dentre os quais foram apontados o apoio familiar, o acolhimento e o engajamento dos educadores, a estrutura administrativa composta por setores de acompanhamento discente, a disponibilizaçáo de recursos institucionais, os processos de trabalho colaborativos, bem como aspectos atitudinais do jovem, como o seu comprometimento com os estudos e sua habilidade em seguir procedimentos e regras. Em especial, o apoio e o engajamento dos pais no percurso educativo do filho parecem ter contribuído, de modo fundamental, para os progressos na escolarização e no desenvolvimento do estudante. Além de participarem ativamente do processo educacional do jovem, os pais o auxiliavam no estudo extraescolar e no gerenciamento dos compromissos da escola (principalmente a máe), possibilitavam acompanhamentos especializados, atividades de natureza artística e esportiva e se constituíram, também, em uma importante referência para o estudante na luta por seus direitos. A contribuição das famílias é indicada de forma recorrente nas pesquisas sobre a edu- 
cação inclusiva e nos relatos de pessoas com TEA, revelando o papel dos parentes no estímulo ao seu desenvolvimento (Grandin \& Panek, 2017), na conscientização sobre o autismo, no incentivo às pesquisas, na oferta de serviços e tratamentos, assim como na luta cotidiana pelos seus direitos contra a discriminação (Grinker, 2010).

Não obstante, a extensa carga horária de estudos, a necessidade de autonomia e o uso de mídias sociais no desenvolvimento de atividades escolares representaram obstáculos para o estudante com TEA visto que requeriam planejamento e organização de sua rotina escolar e reduziam o tempo disponível para o estudo extraclasse. Além disso, caso as instruçôes das atividades escolares não fossem feitas de forma objetiva e detalhada, o aprendizado desse jovem poderia ser comprometido pelo não cumprimento das tarefas, ou pela sua realização de forma inadequada. Essas dificuldades podem estar relacionadas a características do estudante, relativas ao autismo, como a literalidade, o foco em detalhes e a dificuldade em apreender os aspectos globais do conteúdo. A rigidez e as especificidades da abstração apresentadas pelo jovem com TEA também foram associadas pelos entrevistados a dificuldades relacionais, entre ele e os demais estudantes, o que pode ter interferido, inclusive, no desenvolvimento das atividades escolares, tanto em trabalhos em grupo quanto no andamento das aulas. Ao mesmo tempo, as limitaçóes na interação social indicam uma dificuldade em conviver com as diferenças, reflexo da estigmatização presente nos processos de socialização mais amplos. Grinker (2010) discute que a maioria das pessoas com autismo poderia ser mais estigmatizada por não parecer particularmente diferente de outras pessoas em virtude de suas especificidades serem, por vezes, pouco explícitas.

Outro aspecto que representou um empecilho à escolarização técnica desse jovem refere-se à falta de conhecimento anterior dos docentes sobre o TEA e a inexperiência em lecionar para estudantes com essa condição, mesmo no caso dos professores cuja formação acadêmica incluía a licenciatura. A respeito da melhoria dos processos formativos dos professores, a literatura científica indica a necessidade de promover uma formação teoricamente sólida (Garcia, 2013), com uma maior associação entre o conhecimento teórico e didático (Saviani, 2009), sendo indispensável, também, uma definição quanto ao campo de formação em Educação Especial (Garcia, 2013; Kassar, 2014) e a articulação dos elementos curriculares dos cursos de pedagogia e demais licenciaturas (Cruz \& Glat, 2014), entre outros aspectos.

\subsection{Práticas educativas para o estudante Com autismo}

Ao longo do percurso escolar do estudante com TEA no ensino técnico integrado, a instituição federal pesquisada promoveu açóes para favorecer a escolarização desse jovem no curso técnico da área de informática, como será focalizado nos próximos subitens.

Açóes de apoio aos estudantes: A atuação de setores que realizam o acompanhamento do processo educativo dos estudantes foi indicada pelos participantes da pesquisa como intervençốes que promoveram condiçóes de ensino mais adequadas para esse jovem. Nesse sentido, o suporte do setor de acompanhamento psicossocial por meio de açóes de conscientização sobre o autismo junto aos estudantes, do apoio psicológico individual, assim como de orientações aos discentes e mediação de conflitos, possibilitaram um maior acolhimento do jovem com TEA e um sentimento de pertencimento à comunidade escolar. $\mathrm{O}$ grêmio estudantil também atuou, por iniciativa própria, na conscientização sobre o autismo junto a 
estudantes ingressantes na escola. No âmbito do gerenciamento dos compromissos escolares, o acompanhamento do estudante com TEA pelo setor pedagógico parece ter motivado o jovem a organizar sua rotina escolar. Além disso, a estratégia dos pais de vincular uma agenda eletrônica a um relógio que vibrava nos horários dos agendamentos foi apontada como uma intervenção eficaz no sentido de contribuir para mais autonomia do estudante nesse aspecto. Entretanto, os participantes da pesquisa indicaram a ocorrência de dificuldades relacionais entre o jovem com autismo e os colegas, com o decorrer da convivência, e a necessidade de intervençóes mais frequentes no campo das interaçóes sociais. Nesse sentido, Rosin-Pinola e Del Prette (2014) discutem sobre a relevância das habilidades sociais dos professores na escolarização das pessoas com deficiência, considerando que a atuação docente deve promover a articulação da aprendizagem acadêmica ao desenvolvimento socioemocional dos estudantes, de uma forma geral, e contribuir para a melhoria da convivência. Silva e Mendes (2012) apontam que os psicólogos podem auxiliar os docentes, contribuindo para o desenvolvimento das habilidades sociais dos educadores e dos estudantes.

Trabalho colaborativo: A ação articulada entre gestores, docentes, setores de acompanhamento discente, núcleo de apoio à inclusão e pais do estudante com TEA contribuiu para a promoção de uma maior acessibilidade do processo educativo, de acordo com a percepção dos entrevistados. Esse trabalho integrado envolveu o compartilhamento de experiências, proposiçóes coletivas de açóes educacionais, comunicação direta entre professores e pais, bem como suporte à prática docente pelo setor de acompanhamento psicossocial e pelo núcleo pedagógico da instituição. Essa atuação colaborativa resultou na proposição de outras práticas educativas, como a flexibilização da temporalidade do currículo, as adequações das avaliaçóes e a monitoria individualizada. A articulação de diferentes perspectivas na construção e na implementação das açóes educativas, com responsabilidade compartilhada, e o apoio mútuo parecem ter impactado positivamente o processo de escolarização desse estudante no curso técnico integrado, corroborando com achados da literatura que indicam apontamentos comuns (Federico, Herrold, \& Venn, $1999^{11}$ como citado em Mendes, Almeida, \& Toyoda, 2011; Wood, 1998).

Flexibilizaçáo curricular: Considerando as particularidades do jovem com autismo, a instituição técnica federal adotou a flexibilização da temporalidade da matriz curricular e avaliaçóes adaptadas, a partir do segundo ano letivo do estudante no ETI. Nesse sentido, foi elaborado um cronograma anual de disciplinas para o jovem com TEA, com um número menor de matérias, sendo possibilitada a progressão no curso por disciplina e não por série. Com a adoção dessa estratégia, houve uma redução da carga horária anual do curso para esse estudante, o que propiciou a valorização dos seus avanços no processo educativo, mais tempo de estudo extraclasse, assim como a ampliação do tempo livre em sua rotina. A flexibilidade no cumprimento dos elementos curriculares parece ter propiciado uma adequação da temporalidade escolar às particularidades da aprendizagem do estudante com autismo, como a necessidade de um tempo maior para processamento das informaçóes, sua tendência em focar em detalhes e dificuldade em organizar os compromissos escolares. Nas atividades avaliativas das disciplinas, a formulação das questóes foi adaptada por meio da fragmentação dos enunciados com mais de um questionamento e da utilização de perguntas mais diretas e objetivas, evitando-se o uso

${ }^{11}$ Federico, M. A., Herrold, W. G. Jr., \& Venn, J. (1999). Helpful tips for successful inclusion. Teaching Exceptional Children, 32(1), 76-82. 
de linguagem conotativa. Essas adequaçóes contribuíram para uma maior compreensão dos enunciados por parte do estudante com TEA. Além disso, havia a disponibilização de tempo adicional na realização das provas, que não era utilizado com frequência pelo jovem. Após a implementação da flexibilização curricular associada às demais intervençóes institucionais, observou-se um progresso no desempenho escolar do estudante com autismo.

Monitoria individualizada: Como uma estratégia de suporte às dificuldades de aprendizagem do estudante com TEA em áreas específicas, foi implementada uma monitoria individualizada nas matérias técnicas e em uma disciplina de exatas. $\mathrm{O}$ trabalho de monitoria, realizado por graduandos de cada área, possibilitou o acompanhamento das atividades extraclasse, a realização de exercícios, o esclarecimento de dúvidas de forma individualizada e a regularidade dos estudos. No início do processo, os monitores participaram de uma capacitação sobre o TEA promovida por um laboratório de pesquisas e extensão em autismo e, ao longo do processo, foram supervisionados pelos docentes que ministravam a disciplina e orientados pelo setor de acompanhamento psicossocial. Na opiniâo dos participantes da pesquisa, esse suporte individualizado proporcionou que a aprendizagem dos conteúdos ocorresse em um ritmo diferenciado, com procedimentos didáticos mais adequados às particularidades do estudante com TEA, contribuindo para a melhoria do seu desempenho escolar. Além disso, a integração entre o trabalho da monitoria e a prática docente, por meio do acompanhamento das aulas coletivas pelos monitores e do compartilhamento de experiências (entre o professor e o graduando), possibilitou um conhecimento mais aprofundado sobre o processo de aprendizagem do estudante com autismo na disciplina. Entretanto, a falta de institucionalização das açóes inclusivas, como a monitoria individualizada, acarretou obstáculos no desenvolvimento desse suporte, levando à interrupção das aulas, à morosidade na contratação dos monitores, à falta de clareza nas atribuições dos monitores e à percepção desse apoio como um privilégio concedido ao estudante com TEA. Para que as açóes de apoio à escolarização sejam desenvolvidas em condiçóes adequadas, torna-se essencial a reflexão, a conscientização e a participação da comunidade escolar nas políticas que direcionam as práticas educativas na instituição, que pode não ter ocorrido de modo satisfatório na experiência analisada.

Proposta de ensino e procedimentos didáticos: No processo de escolarização do estudante com TEA no ETI, as propostas de ensino de duas disciplinas, uma da área de Ciências Exatas e outra de Ciências da Natureza, contribuíram para a participação e o aprendizado do estudante no curso técnico integrado. Infere-se que essas disciplinas se mostraram mais apropriadas às particularidades do jovem com autismo, uma vez que não exigiram adaptaçóes específicas para ele. $\mathrm{O}$ ensino nessas disciplinas era fundamentado na realização de processos de investigação científica, articulados a situações práticas, na utilização de procedimentos didáticos variados e na valorização do processo de aprendizagem de cada estudante. Na disciplina de Ciências Exatas, diferentes estratégias de ensino eram adotadas, principalmente em pequenos grupos ou em pares, dentre as quais pode-se citar as preleçóes, os debates, a solução de desafios, os registros escritos, a elaboração de sínteses do conteúdo, a realização de experimentos e de formas variadas de avaliação. A disciplina de Ciências da Natureza utilizava a pedagogia de projetos, fundamentada nos constructos teóricos difundidos principalmente pela francesa Josette Jolibert, e seus colaboradores, e pelo espanhol Fernando Hernandéz (Girotto, 2005). Segundo essa concepção, o ensino, a aprendizagem e o conhecimento são circulantes, de forma 
que o docente atua como um facilitador, considerando as contribuiçóes de cada estudante e oportunizando diferentes caminhos de aprendizagem (Hernandéz, 1998). A flexibilidade no processo de aprendizagem, a partir do ensino por projetos, parece ter propiciado que o jovem com TEA desenvolvesse seus estudos em seu ritmo.

Além disso, procedimentos didáticos específicos favoreceram o processo de aprendizado do estudante com autismo no ETI tais como o uso de analogias a situaçóes concretas para explicação de conceitos abstratos, a utilização de instruçóes diretas, objetivas e detalhadas, evitando-se o uso da linguagem conotativa e a habilidade de manejo do professor em diversas situaçóes. Para propiciar o processo educativo, os professores pesquisados utilizaram intervençôes como a eliminação de estímulos distratores, rearranjos da composição de grupos de trabalho, o reforço positivo dos comportamentos, a experimentação de caminhos escolhidos pelo estudante com autismo na resolução dos exercícios e o estabelecimento de combinados sobre o momento de expressão de assuntos de seu interesse nas aulas. Além dessas ações, um procedimento didático foi indicado pelo próprio estudante com TEA e por sua mãe como um método mais adequado às suas particularidades. Esse método, adotado pela mãe para auxiliar o filho nos estudos, consistia em compartimentar o conteúdo, explicando um conceito por vez, seguido da verificação da aprendizagem, com o esclarecimento de dúvidas, e posterior avanço gradual do processo de ensino.

É possível identificar uma proximidade desse procedimento com as orientações de Gomes e Souza (2013), ao abordarem o "controle restrito de estímulos” em pessoas com TEA. As autoras indicam estratégias que auxiliam o estudante a prestar atenção nos aspectos importantes da tarefa, evitando o foco em alguns detalhes apenas, e a organizá-los para que possa compreender, assim, o aspecto global em questão. Infere-se que a compartimentação do conteúdo contribua para que o estudante direcione sua atenção para os elementos relevantes e os organize, gradualmente, no conjunto dos conhecimentos trabalhados. A verificação da aprendizagem também é recomendada, por Gomes e Souza (2013), quando ressaltam que os professores devem estar atentos ao retorno dado pelo estudante e às influências do ambiente no seu desempenho. As autoras indicam, ainda, outras estratégias educativas que consistem em ensinar o estudante com autismo a fazer marcaçóes visuais do que precisa observar, organizar os elementos textuais de maneira explícita, dar orientaçóes verbais para que observe os aspectos relevantes da tarefa, evitar usar estímulos distratores (não essenciais para a atividade proposta) e empregar estímulos visuais e assuntos de interesse do estudante (Gomes \& Souza, 2013).

\section{Discussáo}

A análise do processo de escolarização do estudante com TEA no ensino técnico integrado não pode ser generalizada haja vista, sobretudo, a variedade de manifestaçóes do autismo, mas aponta possibilidades de práticas educativas com esses jovens no contexto da educação profissional. Ao longo do percurso educativo do estudante, a instituição técnica pesquisada não contou com recursos e serviços da Educação Especial, previstos na legislação brasileira, mas buscou promover a acessibilidade por meio de ações construídas coletivamente e concretizadas nos diversos âmbitos da escola. Dessa forma, diferentes setores assumiram as atribuiçóes do AEE, identificando as necessidades educacionais do jovem com TEA e propondo açóes de 
forma articulada, em conjunto à família do estudante, o que acarretou resultados favoráveis à sua escolarização. Entre as ações adotadas pela instituição técnica, duas estratégias destacam-se, principalmente por possibilitarem a adequação do processo educativo do estudante com autismo ao seu estilo de aprendizagem: a flexibilização curricular e a monitoria individualizada. $\mathrm{Na}$ literatura científica, a flexibilização dos currículos é um tema controverso que envolve diferentes concepçóes (Garcia, 2006; Glat \& Blanco, 2007; Tavares Silva, 2015). Na experiência de escolarização pesquisada, a flexibilizaçáo da temporalidade do currículo manteve os objetivos e os conteúdos ministrados nas disciplinas, não afetando substancialmente os elementos básicos do currículo, conforme pontuado por Heredero (2007). O autor esclarece que as adequações quanto à temporalidade curricular e às avaliaçóes modificam a forma de acesso ao currículo, referindo-se ao como e quando se ensina, e como se avalia.

Quanto à proposta da monitoria acadêmica individualizada, esta pode ser compreendida como uma modalidade de mediação no processo de aprendizagem em que os mediadores estão em uma posição diferenciada em relação aos professores da disciplina: menos verticalizada e, provavelmente, com uma linguagem diferenciada, em função da idade e por ocuparem o papel de estudantes. Esse suporte acadêmico individualizado parece ter beneficiado não só o estudante com autismo, por meio do tempo e da didática distintos, como também os monitores, pela oportunidade de ampliar seus conhecimentos sobre o TEA e desenvolverem habilidades sociais, emocionais e pedagógicas. Todavia, Mendes, Silva e Pletsch (2011) alertam que, ao implementar serviços de apoio aos estudantes com deficiência em outros espaços e tempos escolares, a escola pode não repensar sua prática curricular e o trabalho pedagógico desenvolvido dentro da sala de aula. As autoras questionam que, apesar da inserção de novos sujeitos e serviços na escola regular, observa-se uma rigidez do currículo que leva à dissociação dos processos de ensino e de aprendizagem, e à permanência da concepção de que o estudante com deficiência deve ser "normalizado". Dessa forma, um trabalho educativo diversificado e flexível pode se contrapor à tendência à normalização, ainda presente nas práticas escolares, ao considerar a heterogeneidade humana. Nesse sentido, as propostas de ensino não tradicionais no ETI revelaram-se mais apropriadas para a escolarização do jovem com autismo (e talvez dos demais estudantes) ao oportunizar a construção do conhecimento por diferentes caminhos e tempos escolares.

\section{Conclusótes}

$\mathrm{O}$ acesso reduzido dos jovens com autismo à educação profissional indica a necessidade premente de aprimoramento das práticas educativas das escolas regulares da Educação Básica, principalmente no início da escolarização desses sujeitos. Isso poderia se contrapor à redução das oportunidades formativas decorrentes de uma educação precária, ampliando o ingresso na educação profissional. As escolas ainda precisam avançar no sentido de superar a tradição normalizadora dos sistemas de ensino (Mendes, Silva, \& Pletsch, 2011). De qualquer modo, considerando que a mudança dos sistemas educacionais em direção à perspectiva inclusiva é um processo, o ingresso de jovens com autismo no ETI e a adoção de práticas educativas mais acessíveis a eles representam um avanço na escolarizaçáo de pessoas com TEA, no contexto da educação profissional. A presença de estudantes com autismo, nos cursos técnicos fede- 
rais, pode oportunizar o aprimoramento das concepçóes e das práticas educativas no sentido de torná-las acessíveis à diversidade de jovens que fazem parte da comunidade escolar.

Ao analisar as práticas educativas adotadas com um estudante com TEA no ETI, esta pesquisa apontou para intervençóes que se mostraram eficazes no estudo de caso investigado. O trabalho corrobora achados da literatura científica sobre avanços na aprendizagem de pessoas com autismo a partir da implementação de métodos de ensino não tradicionais, quando propiciam condiçóes adequadas às particularidades desses sujeitos (Gomes \& Souza, 2013). Os resultados deste estudo indicam, ainda, que adequaçóes na temporalidade dos currículos e dos planos de ensino, a adoção de procedimentos didáticos diversificados, que articulem a teoria com situaçóes práticas e utilizem uma linguagem objetiva podem tornar o processo educativo mais acessível aos jovens com autismo. Além disso, esta pesquisa sublinha os apontamentos de Rosin-Pinola e Del Prette (2014) e Silva e Mendes (2012) sobre a importância do suporte às interaçóes sociais e da habilidade de manejo dos educadores para o desenvolvimento socioemocional dos educandos e destaca a contribuição desse apoio para a permanência, a participação e a aprendizagem do jovem com autismo, e dos demais estudantes, no ambiente escolar.

Considerando que a pesquisa em questão se tratou de um estudo de caso, outras investigações podem ser realizadas sobre a escolarização de jovens com TEA em instituiçóes de ensino técnico. $\mathrm{O}$ estudo da condição juvenil das pessoas com autismo também consiste em tema relevante visto que a maior parte das pesquisas aborda o autismo na infância, havendo poucas investigaçôes sobre adolescentes ou adultos com TEA (Guedes \& Tada, 2015). Nessa perspectiva, poderia ser pesquisada a vivência da juventude, por parte dos jovens com TEA, no contexto do ETI. Por fim, no que se refere aos egressos dos cursos técnicos integrados, abre-se também a possibilidade de investigar o ingresso dos jovens com autismo no mundo do trabalho.

\section{REFERÊNCIAS}

American Psychological Association - APA (2014). Manual Diagnóstico e Estatístico de Transtornos Mentais: DSM-5 (5a ed.). Porto Alegre: Artmed.

Asperger, H. (2015). Os "psicopatas autistas" na idade infantil (parte 1). Revista Latinoamericana Psicopatologia Fundamenta, 18(2), 314-338.

Bardin, L. (2011). Análise de conteúdo. Portugal: Ediçóes 70.

Constituição da República Federativa do Brasil de 1988. Recuperado em 20 agosto de 2020 de http:// www.planalto.gov.br/ccivil_03/constituicao/constituicao.htm_

Cordeiro, D. R. C. L. (2013). A inclusão de pessoas com deficiência na rede regular de educação profissional. Dissertação de Mestrado, Faculdade de Filosofia e Ciências, Universidade Estadual Paulista "Júlio de Mesquita Filho”, Marília, São Paulo, Brasil.

Cruz, G. C., \& Glat, R. (2014). Educação inclusiva: desafio, descuido e responsabilidade de cursos de licenciatura. Educar em Revista, 52, 257-273. DOI: https://doi.org/10.1590/0104-4060.32950

Decreto $n^{\circ}$ 7.611, de 17 de novembro de 2011. Dispóe sobre a educação especial, o atendimento educacional especializado e dá outras providências. Recuperado em 20 agosto de 2020 de http:// www.planalto.gov.br/ccivil_03/_Ato2011-2014/2011/Decreto/D7611.htm\#art1 1 
Fadda, G. M., \& Cury, V. E. (2016). O enigma do autismo: contribuiçóes sobre a etiologia do transtorno. Revista Psicologia em Estudo, 21(3), 411-423. DOI: https://doi.org/10.4025/psicolestud. v21i3.30709

Garcia, R. M. C. (2006). Políticas para a educação especial e as formas organizativas do trabalho pedagógico. Revista Brasileira de Educação especial, 12(3), 299-316. DOI: https://doi.org/10.1590/ S1413-65382006000300002

Garcia, R. M. C. (2013). Política de educação especial na perspectiva inclusiva e a formação docente no Brasil. Revista Brasileira de Educação, 18(52), 101-119. DOI: https://doi.org/10.1590/S141324782013000100007

Girotto, C. G. G. S. A. (2005). A (re)significação do ensinar-e-aprender: a pedagogia de projetos em contexto. Núcleos de Ensino da Unesp, 1(1), 87-106.

Glat, R., \& Blanco, L. M. V. (2007). Educação especial no contexto de uma educação inclusiva. In R. Glat (Ed.), Educaçâo inclusiva: cultura e cotidiano escolar (2a ed., pp. 15-35). Rio de Janeiro: 7Letras.

Goessler, D. C. B. (2016). As trajetórias escolares de alunos com necessidades educacionais especiais no Instituto Federal do Paraná: uma análise dos indicadores do Censo Escolar. Dissertaçáo de Mestrado, Centro de Educação, Comunicação e Artes, Universidade Estadual de Londrina, Londrina, Paraná, Brasil.

Gomes, C. G. S., \& Souza, D. G. (2013). Transtorno de Espectro do Autismo de alto funcionamento e aprendizagem de conteúdos acadêmicos. In W. Camargos Jr. (Org.), Síndrome de Asperger e outros Transtornos do Espectro do Autismo de alto funcionamento: da avaliação ao tratamento (pp. 301-314). Belo Horizonte: Artesã Editora Ltda.

Grandin. T., \& Panek, R. (2017). O cérebro autista. Rio de Janeiro: Record.

Grinker, R. R. (2010). Autismo: um mundo obscuro e conturbado. São Paulo: Larousse do Brasil.

Guedes, N. P. S., \& Tada, I. N. C. (2015). A produção científica brasileira sobre autismo na psicologia e na educação. Psicologia: Teoria e Pesquisa, 31(3), 303-309. DOI: https://doi.org/10.1590/010237722015032188303309

Heredero, E. S. (2007). Las adaptaciones curriculares de pequeno porte o no significativas en el contexto brasileño. Revista Ibero-Americana de Estudos em Educação, 2(2), 103-116. DOI: https://doi. org/10.21723/riaee.v2i 2.463

Hernandéz, F. (1998). Transgressão e mudança na educação. Recuperado em 19 de fevereiro de 2019 de http:/docs.fct.unesp.br/docentes/geo/necio_turra/PESQUISA\%20EM\%20GEOGRAFIA/ FERNANDO\%20HERNANDEZ\%20-\%20PEDAGOGIA\%20DE\%20PROJETOS.pdf

Instituto Nacional de Estudos e Pesquisas Educacionais Anísio Teixeira (2015). Sinopse Estatística da Educação Básica 2014. Brasília: Inep. Recuperado em 1 de maio de 2018 de http://inep.gov.br/ sinopses-estatisticas-da-educacao-basica

Instituto Nacional de Estudos e Pesquisas Educacionais Anísio Teixeira (2016). Sinopse Estatística da Educação Básica 2015. Brasília: Inep. Recuperado em 1 de maio de 2018 de http://inep.gov.br/ sinopses-estatisticas-da-educacao-basica

Instituto Nacional de Estudos e Pesquisas Educacionais Anísio Teixeira (2017). Sinopse Estatística da Educação Básica 2016. Brasília: Inep. Recuperado em 1 de maio de 2018 de http://inep.gov.br/ sinopses-estatisticas-da-educacao-basica 
Instituto Nacional de Estudos e Pesquisas Educacionais Anísio Teixeira (2018). Sinopse Estatística da Educação Básica 2017. Brasília: Inep. Recuperado em 31 março de 2020 de http://inep.gov.br/ sinopses-estatisticas-da-educacao-basica

Instituto Nacional de Estudos e Pesquisas Educacionais Anísio Teixeira (2019). Sinopse Estatística da Educação Básica 2018. Brasília: Inep. Recuperado em 31 de março de 2020 de http://inep.gov.br/ sinopses-estatisticas-da-educacao-basica

Kanner, L. (2012). Os distúrbios autísticos do contato afetivo. In A. Sanches (Ed.), Autismos (2a ed., pp. 111-183). São Paulo: Escuta.

Kassar, M. C. M. (2014). A formação de professores para a educação inclusiva e os possíveis impactos na escolarização de alunos com deficiência. Cadernos Cedes, 34(93), 207-224. DOI: https://doi. org/10.1590/S0101-32622014000200005

Kassar, M. C. M., \& Rebelo, A. S. (2011). O "especial” na educação, o atendimento especializado e a educação especial. Seminário Nacional de Pesquisa em Educação Especial: prática pedagógica na educação especial: multiplicidade do Atendimento Educacional Especializado. Nova Almeida/ Serra, Espírito Santo, Brasil, 6.

Lei $n^{\circ}$ 9.394, de 20 de dezembro de 1996. Estabelece as Diretrizes e Bases da Educação Nacional. Recuperado em 31 março de 2020 de http://www.planalto.gov.br/ccivil_03/leis/L9394.htm\#\%20 art92

Lei no 12.764, de 27 de dezembro de 2012. Institui a Política Nacional de Proteção dos Direitos da Pessoa com Transtorno do Espectro Autista e altera o $\$ 3^{\circ}$ do art. 98 da Lei n. 8.112, de 11 de dezembro de 1990. Recuperado em 31 de março de 2020 de http://www.planalto.gov.br/ccivil_03/_ato20112014/2012/lei/l12764.htm

Lei no 13.146, de 6 de julho de 2015. Institui a Lei Brasileira de Inclusão da Pessoa com Deficiência (Estatuto da Pessoa com Deficiência). Recuperado em 31 de março de 2020 de http://www. planalto.gov.br/ccivil_03/_ato2015-2018/2015/lei/l13146.htm

Lima, S. M., \& Laplane, A. L. F. (2016). Escolarização de alunos com autismo. Revista Brasileira de Educação especial, 22(2), 269-284. DOI: https://doi.org/10.1590/S1413-65382216000200009

Mendes, E. G., Almeida, M. A., \& Toyoda, C. Y. (2011). Inclusão escolar pela via da colaboração entre educação especial e educação regular. Educação em Revista, 41, 80-93.

Mendes, G. M. L., Silva, S. C. T, \& Pletsch, M. D. (2011). Atendimento educacional especializado: por entre políticas, práticas e currículo um espaço tempo de inclusão? Revista Contrapontos, 11(3), $255-265$.

Oliveira, R. I. (2014). Conta-me como foi: percursos escolares de jovens e adultos com deficiência e transtorno global do desenvolvimento, mediados por processos de compensaçâo social. Tese de Doutorado, Centro de Educação, Universidade Federal do Espírito Santo, Vitória, Espírito Santo, Brasil.

Política Nacional de Educação Especial na Perspectiva da Educação Inclusiva de 2008. Recuperado em 31 de março de 2020 de http://portal.mec.gov.br/index.php?optionm=com_ docman\&view=download \&alias=16690-politica-nacional-de-educacao-especial-na-perspectivada-educacao-inclusiva-05122014\&Itemid\%20=30192

Rodrigues, J. C. (2014). Caminhos de formação em música de estudantes com Transtorno do Espectro do Autismo em uma escola técnica em música. Dissertação de Mestrado, Instituto de Ciências da Arte, Universidade Federal do Pará, Belém, Pará, Brasil. 
Rosin-Pinola, A. R., \& Del Prette, Z. A. P. (2014). Inclusão escolar, formação de professores e a assessoria baseada em habilidades sociais educativas. Revista Brasileira de Educação Especial, 20(3), 341-356.

Saviani, D. (2009). Formação de professores: aspectos históricos e teóricos do problema no contexto brasileiro. Revista Brasileira de Educação, 14(40), 143-155.

Schmidt, C. (2017). Transtorno do Espectro Autista: onde estamos e para onde vamos. Psicologia em Estudo, 22(2), 221-230.

Silva, A. M., \& Mendes, E. G. (2012). Psicologia e inclusão escolar: novas possibilidades de intervir preventivamente sobre problemas comportamentais. Revista Brasileira de Educação Especial, 18(1), 53-70. DOI: https://doi.org/10.1590/S1413-65382012000100005

Silva, I. M. A. (2011). Políticas de educação profissional para pessoa com deficiência. Tese de Doutorado, Faculdade de Educação, Universidade Federal de Minas Gerais, Belo Horizonte, Minas Gerais, Brasil.

Silva, I. M. A., \& Dore, R. (2016). A evasão de estudantes com deficiência na Rede Federal de Educação Profissional em Minas Gerais. Revista Educação Especial, 29(54), 203-214. DOI: http://dx.doi. org/10.5902/1984686X19152

Tavares Silva, F. C. T. (2015). Algumas notas de análise sobre a escolaridade dos alunos com deficiência: por entre adaptaçóes, flexibilizaçóes e diferenciaçóes curriculares. In A. A. Ayache, C. R. Baptista, D. Rodrigues, D. M. de Jesus, E. G. Mendes, G. M. Jannuzzi, \& V. A. da Costa (Eds.), Educação Especial Inclusiva: legados históricos e perspectivas futuras (pp. 83-96). São Carlos: Marquezini \& Manzini: ABPEE.

Wood, M. (1998). Whose job is it anyway? Educational roles in inclusion. Exceptional Children, 64(2), 181-195.

Recebido em: 28/07/2020

Reformulado em: 30/07/2020

Aprovado em: 10/09/2020 
VASCONCELLOS, S.P.; RAHME, M.M.F.; GONÇALVES, T.G. G.L. 